\title{
A STUDY OF EMOTIONAL INTELLIGENCE COMPETENCIES POSSESSED BY THE YOUTH
}

\author{
Dr. Mona Mehta \\ Ms. Rakhi Dasgupta \\ Ms. Rutu Modi
}

\begin{abstract}
Emotional Intelligence Competencies amongst undergraduate university youth at a Higher Education Institution is one of the areas less ventured upon. Gardner (1983; 1991) reported that business-related graduate programmes focused primarily on indicators of individual competence such as logical and linguistic intelligence, with less attention being given to spatial, interpersonal and naturalist forms of intelligence. Later research reported increased calls from industry to make curricula more relevant to 'today's global workplace' through improved instruction in communication, leadership, as well as intrapersonal and interpersonal skills (Cherniss 1999; Doria, Rozanski and Cohen, 2003; Jaeger 2003; Myers and Tucker 2005). Lately, Daniel Goleman's research on emotional intelligence as a predictor of work performance has emerged (Goleman 1998, 2000; Weisinger, 1998) and continues to be highly influential. The traditional approach by educationists, however, has been to focus on logical and linguistic intelligence. This view have been challenged by many studies recently where researchers are beginning to argue that interpersonal and intrapersonal competencies and Emotional Intelligence (EQ) may be more important for success. Educational institutions have traditionally focussed primarily on logical and linguistic intelligence, with less attention given to other types of intelligence. Yet many researchers are beginning to argue that intrapersonal and interpersonal competencies, or emotional intelligence, may be more important for success in life than logical or linguistic intelligence (Tucker, Sojka, Barone \& McCarthy, 2000). Though the concept of emotional intelligence was first introduced in organizations, its relevance made the concept an inevitable concept of consideration in the educational sector too. Developing emotional intelligence skills amongst youth is very important because it can positively affect academic achievement not only during the session they are taught, but in subsequent years as well (Elias, Brune, Butler, Blum \& Schumler, 1997). According to Caruso, Mayer and Salovey (2002), emotional intelligence skills and knowledge can be developed and learned and it matters most in times of change. Emotional intelligence is an ability to recognize one,,s own feeling and those of others, for motivating self as well as one,,s relationship with others. Studies (e.g. Ediger, 1997; Parker, Summerfeldt, Hogan \& Majeski 2004)) have shown that the acquisition of emotional intelligence skills can significantly contribute to positive thinking in students and increase their ability to concentrate for a long time. The present research was thereby undertaken with the main aim of investigating the emotional intelligence competencies by the youth. Descriptive research design was taken up with questionnaire as a tool for the present
\end{abstract}


research. Convenience sampling technique was adopted for the study. The sample consisted of undergraduate students from the Faculty of Family and Community Sciences. Descriptive as well as relational statistics was used for the present research. The main outcome of the study will be that emotions can purposely be utilized and orchestrated to work at the advantage of the students by guiding their train of thought, impacting their thinking, cascading into guiding their behaviour and action, in this way increasing and boosting their results and success rate at university.

Keywords: Emotional intelligence, intrapersonal and interpersonal competencies, skills

\section{INTRODUCTION}

Salovey and Mayer first used the term "emotional intelligence" and stated it in four domains: knowing one's emotions, knowing others' emotions, handling one's emotions, and handling others' emotions ${ }^{[11]}$. Recently, psychologists have been paying attention to the complexity of the construct and describing it in terms of multiple capabilities and competencies ${ }^{[6,7]}$.

Emotional intelligence is a "convenient phrase" that focuses on human talent ${ }^{[2]}$. However, EI has been challenged for having too broad a definition of all positive personality traits that result in positive outcomes. The famous model proposed by Goleman ${ }^{[6,7]}$ does not mention the ways to distinguish the level of a person's EI. Zeidner et al. ${ }^{[14]}$ state that the definition of EI may be mixed with social intelligence (SI) as both constructs measure the individual differences relative to how much an individual exhibits traits. In their review, Zeidner et al. ${ }^{[14]}$ point out that EI is mostly defined as a stable quality of the individual. However, most of the adaptive responses to different emotional circumstances are dynamic and situation dependent. In this sense, using the causal model among the constructs of EI is meaningless. Hence, it would be better to define EI as a set of supporting adaptations of emotional skills, which the proponents of EC emphasize, that would form the causal, positive outcomes ${ }^{[13]}$.

Carroll ${ }^{[3]}$ comments that the EI construct lacks the comprehensive models established for conventional mental abilities and Zeidner et al. ${ }^{[13]}$ echo that it is difficult to differentiate EI from multiple constructs due to the difficulty in conceptualization. The developmental psychologists find that the term "intelligence" focuses more on the "mental ability" ${ }^{[12]}$ and characteristics of the person ${ }^{[10]}$ without the notion of contextual influences on the individual. Most recently, there has developed a separate strand of research, focusing on the conceptions, awareness, understanding, and applications of the emotions in social interactions ${ }^{[5]}$. EI can thus be viewed as a snapshot of emotional competencies and the term "emotional competence" is adopted in a more neutral way [9]. The word "competence" signifies the 
generalization of the most emotive situations ${ }^{[13]}$. As such, we agree with Ciarrochi and Scott [4] that emotional competence includes the ability to identify emotions and an individual difference in how effectively people deal with emotions and emotionally charged problems.

Emotional Intelligence is essential for any student, as they are the leaders in their own life and drive either their success or failure of obtaining a degree. As any student would know, the motivation to success has to lie within themselves as the demands and stress levels are all part of the pursuit of educational success. The university and their staff complement act as a medium to obtain this degree, therefore, they are the management of the organization. The university at which the current research was undertaken, has recently embarked on a strategic initiative to determine best practice with respect to Teaching and Learning, and is developing graduate attributes aimed to address some of the needs of industry and society at large. While students have been expected to critically engage with theory and apply their minds to resolve broader societal problems, they are expected to be able to possess skills in perceiving and understanding their own emotions, others ${ }^{\text {ee }}$ emotions, effectively expressing these emotions, incorporating emotional information in reasoning, planning and decision-making, effectively controlling emotions, and being able to emotionally read situations in order to ensure that they become aware of the impact of their emotions on attitudes, behaviour and performance. Educational institutions have traditionally focussed primarily on logical and linguistic intelligence, with less attention given to other types of intelligence. Yet many researchers are beginning to argue that intrapersonal and interpersonal competencies, or emotional intelligence, may be more important for success in life than logical or linguistic intelligence (Tucker, Sojka, Barone \& McCarthy, 2000). In addition, studies of managerial derailment indicate a lack of emotional intelligence. Derailment is frequently attributed to personality characteristics (such as a lack of self-awareness), an inability to change, poor treatment of others and problems with interpersonal relationships. The aim of this research is to examine Emotional Intelligence competencies possessed by the youth ${ }^{[12]}$.

Goleman (1995) has described EQ in terms of knowing what you are feeling and being able to manage these feelings without being swamped. Hence, it is essential for the students to possess these qualities, in order to meet deadlines and to maintain a balance between their personal life and the stressful demand of university life ${ }^{[6]}$. 
For the present study Emotional Intelligence was measured in different aspects like Emotional self awareness, Emotional Self Control, Conflict Management, Self confidence, Empathy, Motivation, Social skills.

1. Emotional Self awareness defined as recognizing one's own feelings and how they affect one's performance.

2. Emotional self -confidence referred to the strong sense of one's self worth and capabilities.

3. Emotional Self control defined as staying clear headed, calm and balancing feelings for the achievement of desired goals.

4. Empathy defined as the ability to sense other people's emotions, coupled with the ability to imagine what someone else might be thinking or feeling

5. Conflict Management defined as negotiating and resolving disagreement between two or more people or groups.

6. Motivation referred to as an inner emotional tendency of an individual that guides or facilitates them to reach their desired goals.

7. Social Skills defined as the skills needed to handle and influence other peoples emotions effectively.

\section{METHODOLOGY}

The research design of the study was descriptive in nature. The present study was conducted in Vadodara city of Gujarat state. The students of the Maharaja Sayajirao University of Baroda were the unit of inquiry for the study. The total sample size was $\mathbf{1 0 0}$. Convenience Sampling Technique was adopted for the present study as the researcher selected the samples that were willing to respond the data. For the present study, questionnaire was selected as a tool for data collection. The data was analyzed by utilizing categorization, coding, tabulation and descriptive as well as relational statistics.

The tool was constructed complying the objectives of the study. Various sources like books, journals and electronic media were used to develop the tool of the present research. The information gathered from the questionnaire was divided into the following sections.

\section{Section I: Background Information}

This section incorporated the information regarding the background characteristics of the 
respondents i.e. personal profile which included age, gender, educational qualification, and family profile like type of family, size of family and total monthly family income.

\section{Section II: Information on the Aspect of Emotional Intelligence of the University Teachers}

This scale comprised of the items related to the selected aspects of Emotional Intelligence of university teachers like emotional self awareness, self confidence, self control, empathy, conflict management, motivation and social skills. The various statements formulated with regards to the scale on self-awareness included feelings related to 'expressing emotions', 'reaction to various emotion', 'balancing mood'. The scale on self-control included statements related to 'having self-discipline', 'thinking clearly', 'adjusting according to circumstances', 'managing feelings'. The scale on Conflict management comprised of statements related to 'finding best solution', 'avoiding conflict', 'handling situation' and 'encouraging discussion'. The scale on Self-confidence included statements on 'having presence of mind', 'making sound decisions' and 'handling multiple demands'. The scale on Empathy included statements related to 'understanding needs of others', 'showing sensitivity', 'being good listener', 'dealing effectively with the students and colleagues'. The scale on Motivation comprised statements on 'continuous learning', 'seizing opportunities', 'mentoring', 'improving self'. The scale on social skills included statements related to 'taking initiative', 'working comfortably with different people', 'using various medium for communication', 'guiding the performance'. The respondents were required to state the level of aspects of Emotional Intelligence possessed by them on each of these scales with a response structure of 'Always', 'Sometimes' and 'Never'. Scores of 3 through 1 was

attributed respectively to these responses. Higher scores on Aspects of Emotional Intelligence reflected High Extent of Emotional Intelligence and vice versa.

\section{FINDING AND DISCUSSION}

\section{SECTION- I}

\section{Demographic data of the respondents}

This section includes information with reference to the demographic data of the respondents. It includes personal data and the family data of the respondents. The findings associated to the personal data of the respondents included their age, gender and education qualification. The family data of the respondents included type of family, size of family and total monthly income.

Graph-1: Distribution of the respondents according to their personal demographic data. 


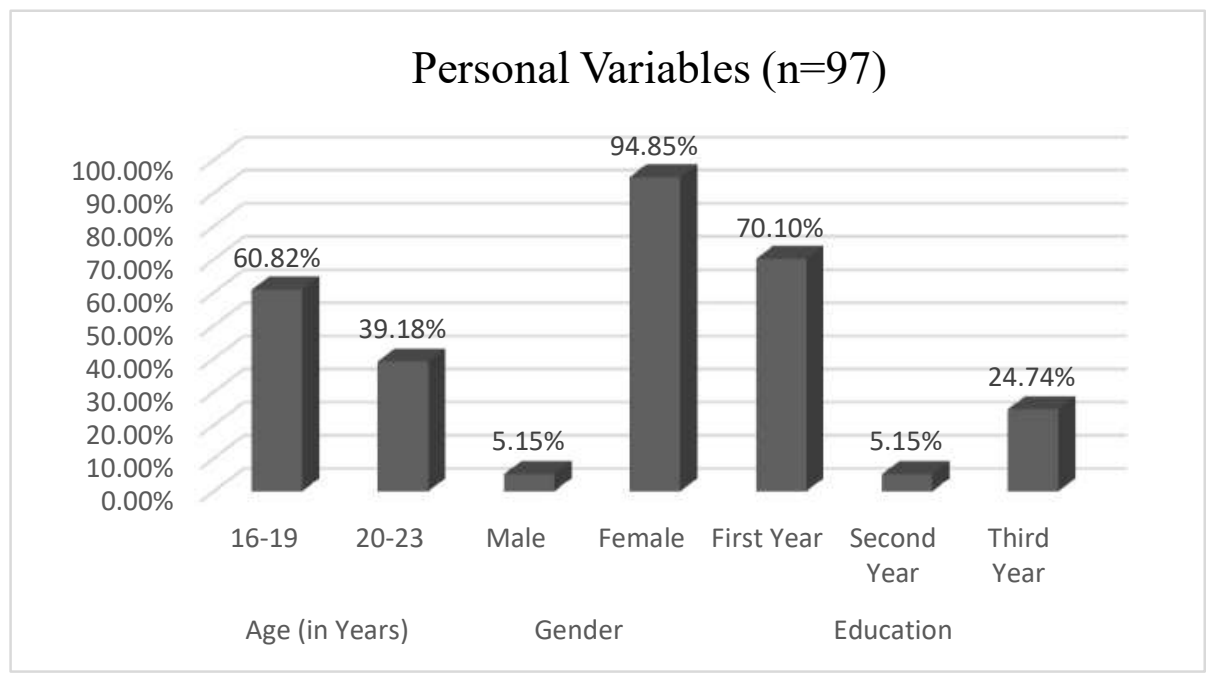

The findings revealed that more than one- half (60.82per cent) of the respondents were aged between 16 years to 19 years. And the remaining more than one -third (39.18 per cent) respondents were aged between 20 years to 23 years. It was also found that majority $(94.85$ per cent) of the respondents were females compared to males. With regards to educational qualification, it was found that more than two -third (70.10 per cent) of the respondents were pursuing their education in first year.

Graph-2: Distribution of the respondents according to their family demographic data.

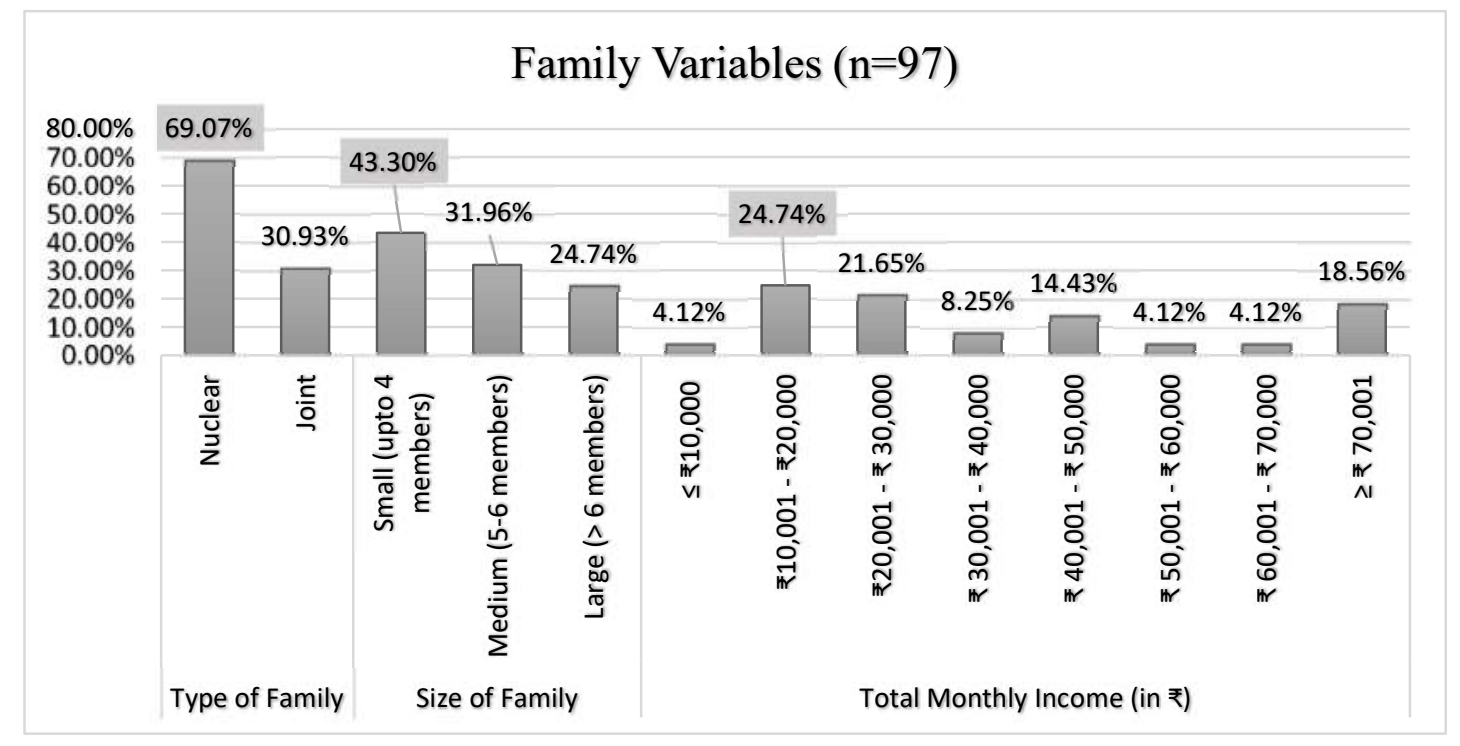

The findings of the study revealed that more than one half ( 69.07 per cent) of the respondents belonged to nuclear family. Little less than one half (43.30 per cent) of the respondents were having small family consist upto 4 members. A probe on the monthly income of the family of 
the respondents highlighted that one fourth (24.74 per cent) of the respondents had their monthly family income ranged between Rs.10,001 to Rs. 20,000.

\section{Graph-3: Distribution of respondents according to the Weighted Mean Scores for} aspects of Emotional Intelligence- "Emotional Self-Awareness"

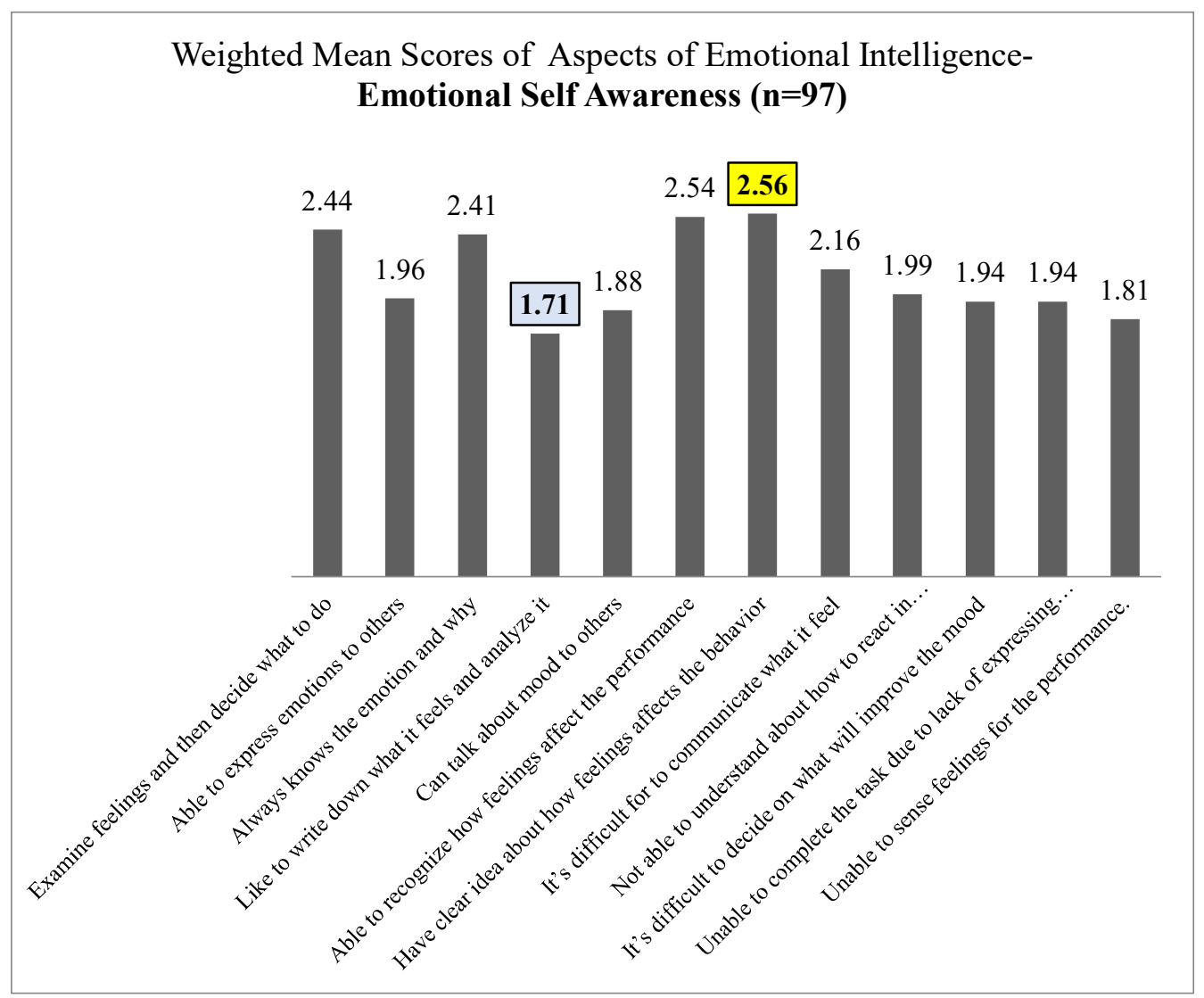

While comparing the Weighted Mean Scores of the respondents under "Emotional Self Awareness" category the findings reported that "Having clear idea about how feelings affect the behavior"(2.56) ranked first in order, followed by "Ability to recognize how feelings affect the performance" (2.54) and "Examining feelings and then deciding what to do" (2.44) respectively. 
Towards Excellence: An Indexed, Refereed \& Peer Reviewed Journal of Higher Education /

Dr. Mona Mehta, Ms. Rakhi Dasgupta \& Ms. Rutu Modi / Page 468-481

Graph-4: Distribution of respondents according to the Weighted Mean Scores for aspects of Emotional Intelligence-"Emotional Self-Control”

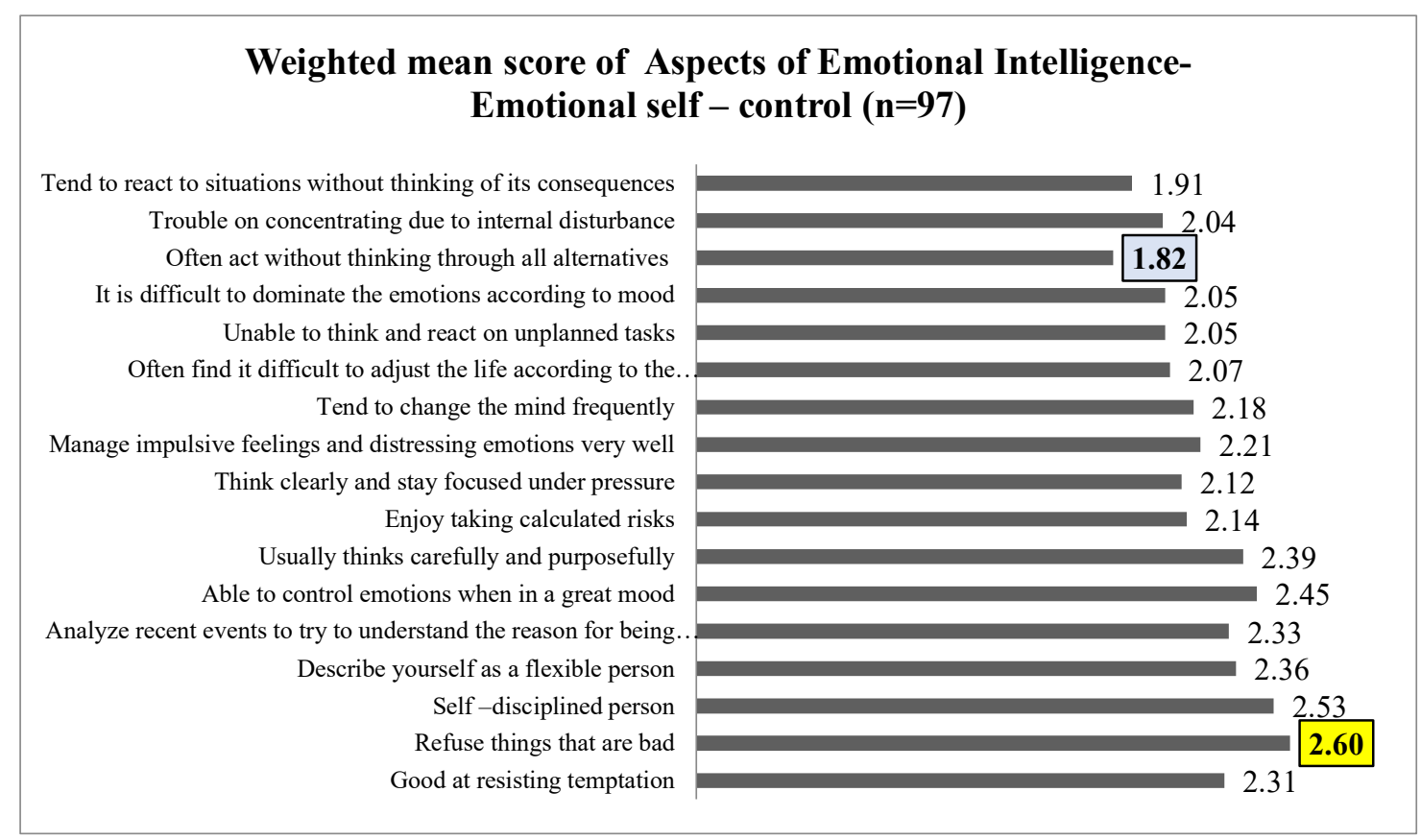

The findings under "Emotional Self-Control" category reported that the respondents refused things that were bad" (2.60), were "self-disciplined person's(2.53) and were able to control emotions when they were in a great mood"(2.45) respectively.

\section{Graph-5: Distribution of respondents according to the Weighted Mean Scores for aspects of Emotional Intelligence- "Conflict-Management"}

\section{Weighted mean scores of Aspects of Emotional Intelligence- Conflict Management $(n=97)$}

Difficult to help others to solve their conflicts

Unable to agree on other's decision

Difficult to conclude on one opinion

Stand for inculcating the own opinion

Avoid communicating with others to avoid conflict

Encourage debate and open discussion

Spot potential conflicts, bring disagreements in to open

Tend to back down even if its right

Avoid the differences of opinion as much as possible

Handle difficult students and tense situations with

Try to make up any dispute, seems less important

Creatively finds out best solution for everyone

Go with other's decision to end-up conflicts

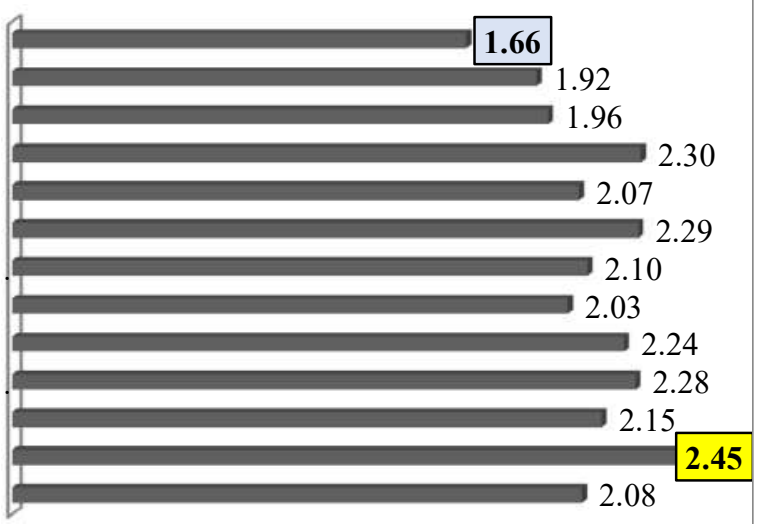

The weighted mean scores of the respondents under "Conflict-Management" category reported that being creative" (2.45) ranked first in order, followed by Standing for 
inculcating their own opinion"(2.30) and "Encouraging debate and open discussion"(2.29) with the students respectively.

\section{Graph-6: Distribution of respondents according to the Weighted Mean Scores for aspects of Emotional Intelligence- "Self-Confidence".}

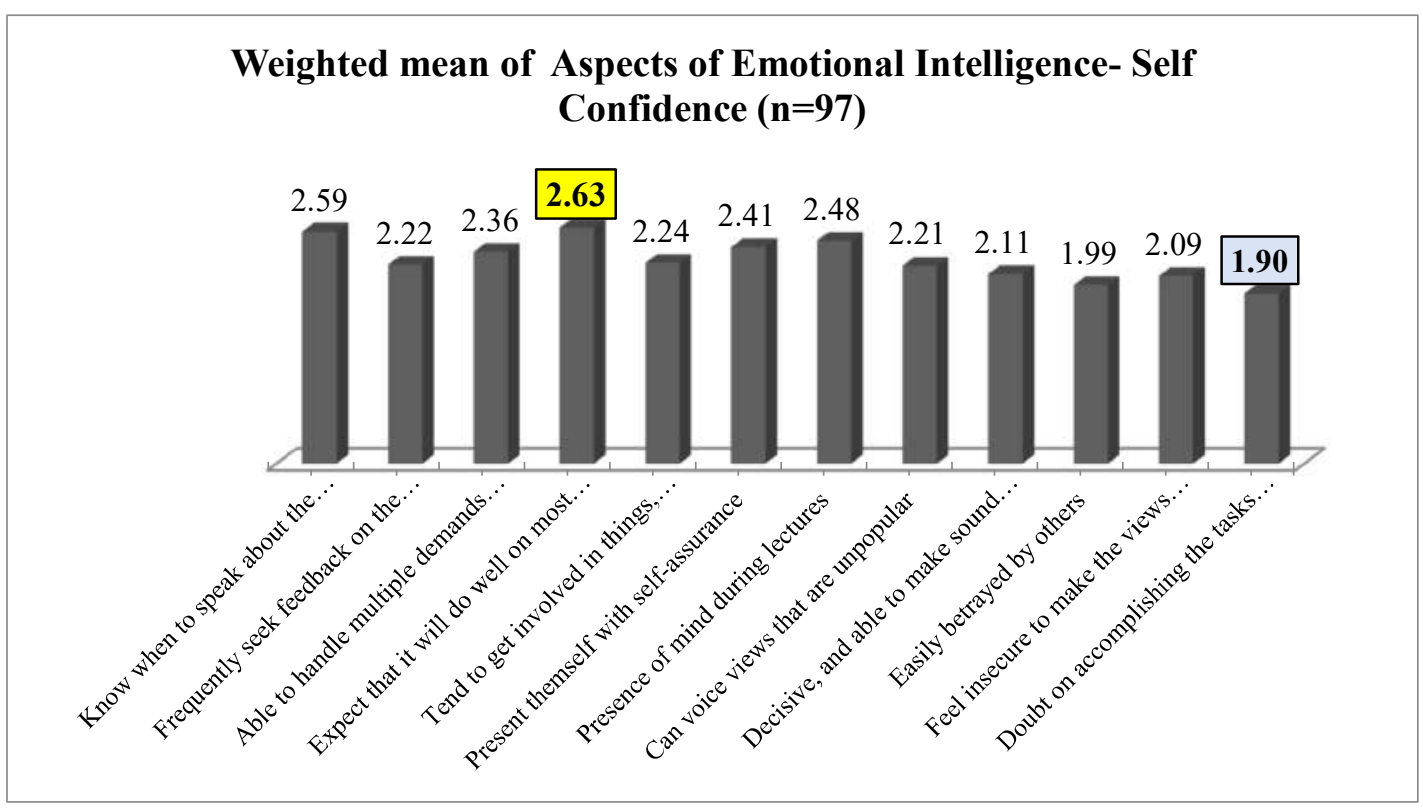

The findings reported that the respondents expected to do well on most things that were tried"(2.63) ranked first in order, and also "knew when to speak about personal problems to others"(2.59) and having presence of mind during lectures"(2.48) respectively.

Graph-7: Distribution of respondents according to the Weighted Mean Scores for aspects of Emotional Intelligence- "Empathy"

\section{Weighted mean score of Aspects of Emotional Intelligence- Empathy (n=97)}

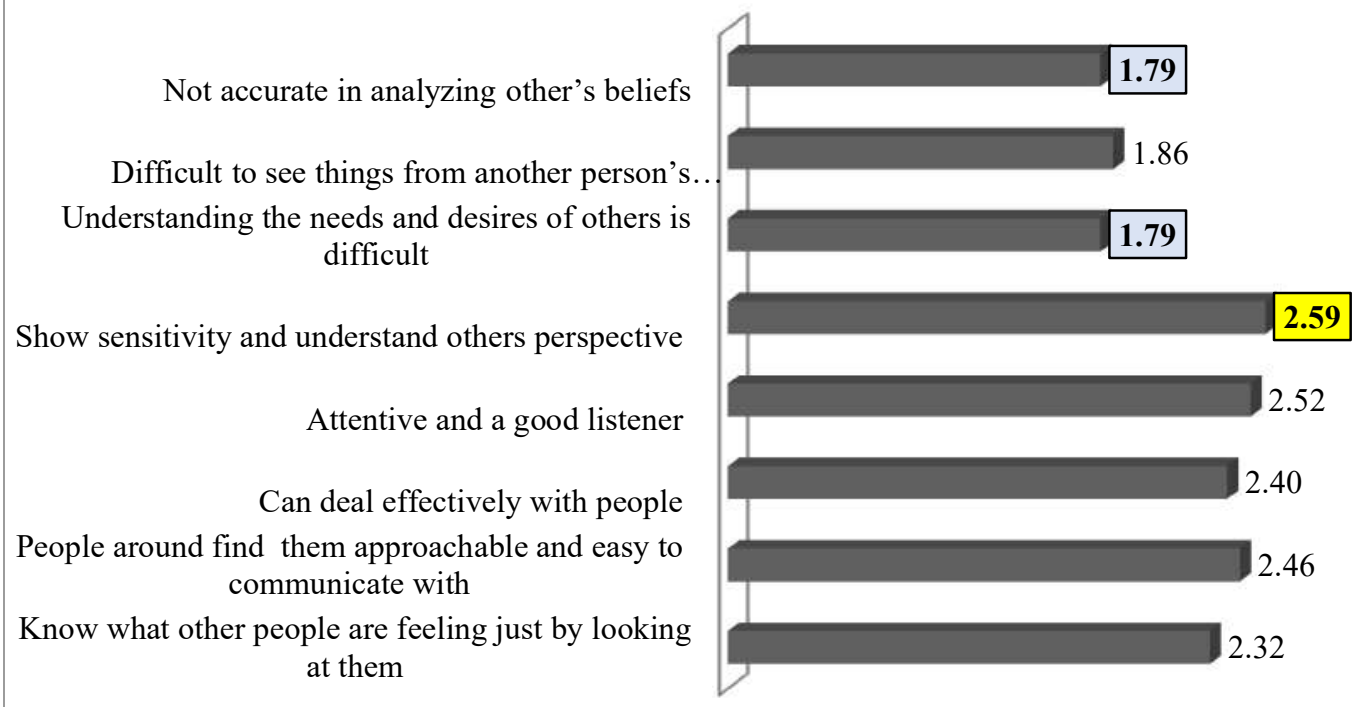

March, 2021. VOL.13. ISSUE NO. 1 https://hrdc.gujaratuniversity.ac.in/Publication 
The findings reported that under the various aspects of Empathy revealed that sensitivity and understanding others perspective ranked first in order. Moreover, people also found them approachable and easy to communicate with and could deal effectively with people respectively.

\section{Graph-8: Distribution of respondents according to the Weighted Mean Scores for aspects of Emotional Intelligence- "Motivation"}

\section{Weighted mean score of Aspects of Emotional Intelligence- Motivation ( $\mathbf{n = 9 7})$}

Do not make personal or group sacrifices to meet a larger organizational goal

Do not try to improve the performance by eliciting feedback.

Unable to quickly reorient the thinking in case of uncertain problems.

Motivate by imagining a good outcome to tasks take on

Acknowledge and reward friend's strengths, accomplishments, and development

Operate from hope of success rather than fear of failure

Continuously learn in order to improve the performance

Pursue information to reduce uncertainty and find ways to do better

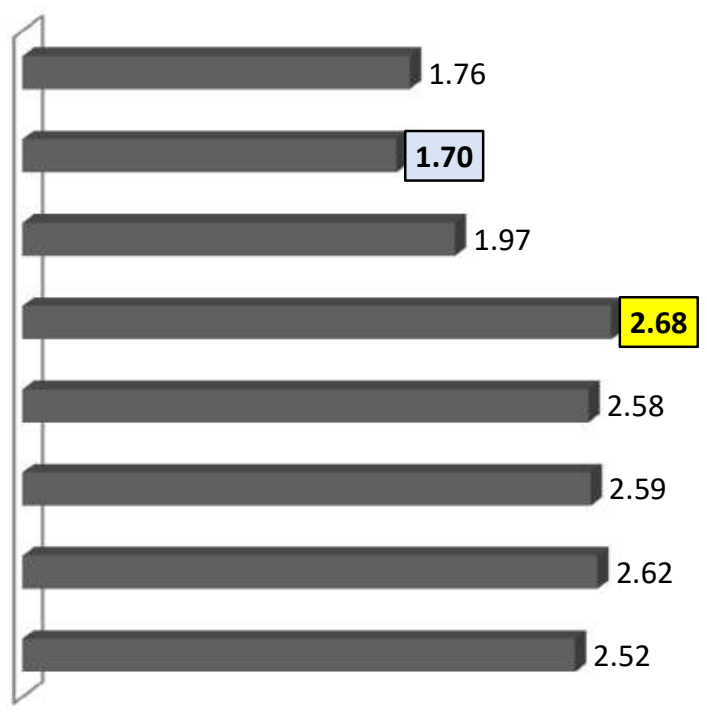

While comparing the weighted mean scores of the respondents under "Motivation" category the findings reported that the respondents "motivated by imagining a good outcome to tasks they took on" (2.68) followed by "Continuously learning in order to improve the performance" (2.62) and always operated from hope of success rather than fear of failure (2.59) respectively.. 
Towards Excellence: An Indexed, Refereed \& Peer Reviewed Journal of Higher Education /

Dr. Mona Mehta, Ms. Rakhi Dasgupta \& Ms. Rutu Modi / Page 468-481

Graph-9: Distribution of respondents according to the Weighted Mean Scores for aspects of Emotional Intelligence- "Social-Skills"

\section{Weighted mean score of Aspects of Emotional Intelligence- Social Skills $(\mathbf{n}=97)$}

Difficult for to accomplish tasks that includes high social interaction

Not able to understand and meet the expectations of others.

Collaborate in sharing plans, information, and resources.

Easily lead the friends during their difficulty in learning.

Make use of skill communication to get the desired response.

Able to put across my messages effectively.

Take initiative to start conversation with new classmates.

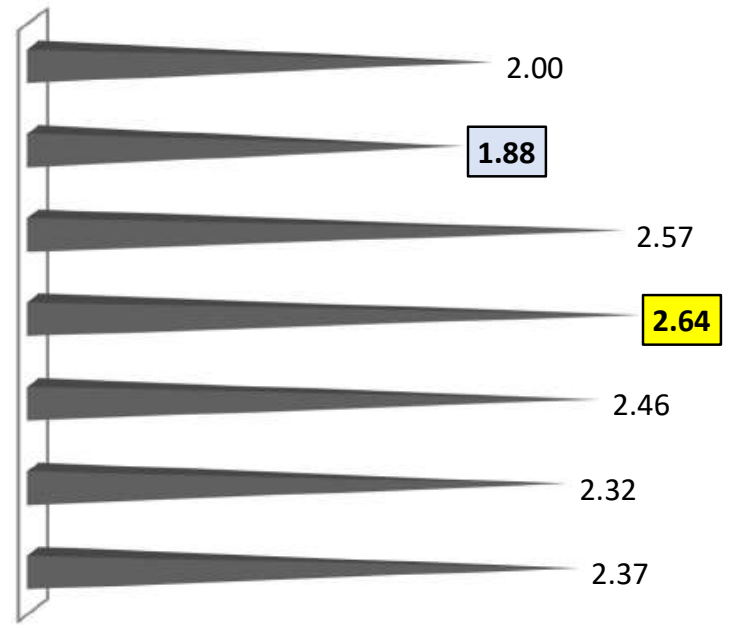

While comparing the weighted mean scores of the respondents under "Social-Skills" category the findings reported that the aspects of Emotional intelligence under" Easily lead the friends during their difficulty in learning" (2.64) "Collaborate in sharing plans, information, and resources" (2.57) and "Make use of skill communication to get the desired response" (2.46) respectively.

\section{Graph-10: Distribution of respondents according to the Weighted Mean Scores} obtained on the level of Aspects of Emotional Intelligence.

\section{Overall Weighted Mean Scores of levels of Aspects of Emotional Intelligence- $(n=97)$}
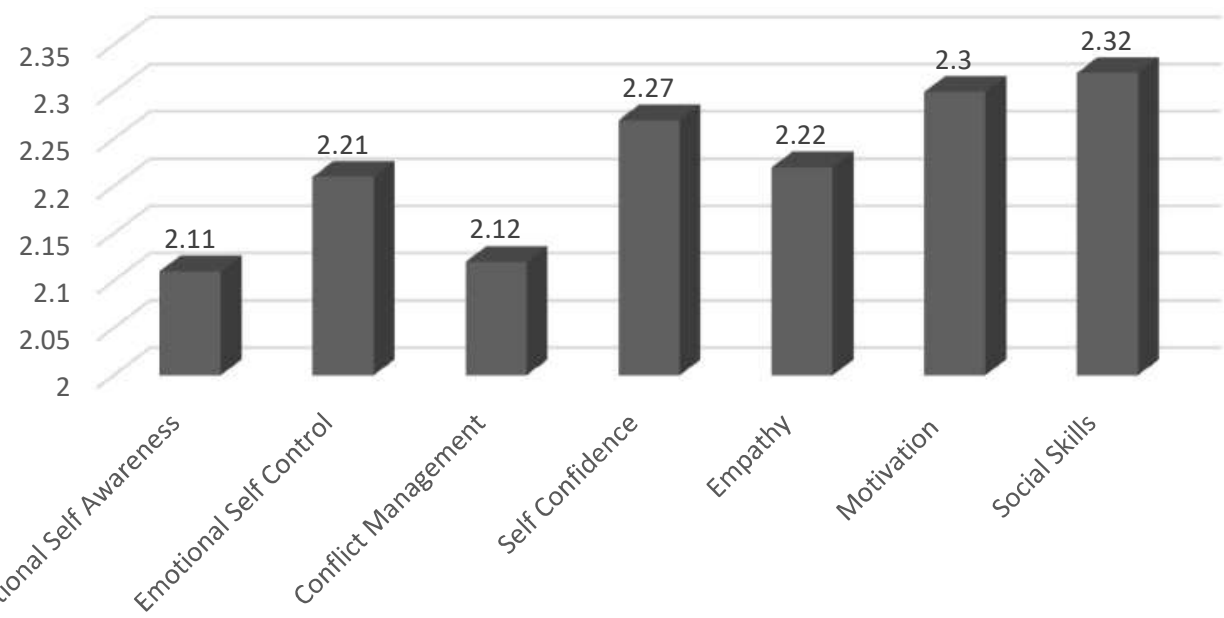
The overall weighted mean of level of aspects of emotional intelligence was found high in social skills which shows that Emotionally intelligent youth are able to develop social relationships well, reduce stress and frustration on problems they experienced, understand other people's emotions, and prevent or reduce destructive behaviour and develop effective competencies to deal with everyday life situations.

\section{CONCLUSION}

Emotional Intelligence is gaining fast momentum and the importance and awareness around this arena is steadily growing. Each individual possess emotions which either drives them to their success or failure. Having said this, if an academic student can utilize, manage and filter their emotions in positive ways to deal with the best or adverse situations, it is likely that this could influence their adaptation and successful completion of academic courses.

The traditional approach by educationists has been to focus on logical and linguistic intelligence. This view have been challenged by many studies recently where researchers are beginning to argue that interpersonal and intrapersonal competencies and emotional intelligence may be more important for success. Studies of managerial derailment have been attributed to personality characteristics such as inability to change, poor treatment of others and interpersonal relationship problems. Education has been built on mindset of logic and analysis. For a long time the outcomes within an educational framework has focussed on developing graduates and students with sound knowledge and the ability to be creative, adaptive and practical. Very seldom is this the case where most of the emphasis is placed on cognitive factors. Instead it has been shown that over $90 \%$ of success has been attributed to non cognitive factors (Kemper, 1999). Developing of emotional intelligence of students is not seen as the responsibility of an educational system. This view fails to take into account the fact that students relate emotionally to instruction and determines to a large extent whether they learn or want to learn. Feelings relate directly to thinking which guides human behaviour. EQ is created by high quality thinking which can lead to high quality emotions (Elder, 1997). 
Towards Excellence: An Indexed, Refereed \& Peer Reviewed Journal of Higher Education /

Dr. Mona Mehta, Ms. Rakhi Dasgupta \& Ms. Rutu Modi / Page 468-481

\section{Bibliography}

1. Bar-On R. The Emotional Intelligence Inventory (EQ-i): Technical Manual. Toronto, Canada: Multi-Health Systems; 1997. [Google Scholar]

2. Boyatzis RE, Goleman D, Rhee K. Clustering competence in emotional intelligence: insights from the Emotional Competence Inventory (ECI) In: Bar-On R, Parker JDA, editors. Handbook of Emotional Intelligence. San Francisco, Calif, USA: Jossey-Bass; 1999. pp. 2-35. [Google Scholar]

3. Carroll JB. Human Cognitive Abilities: A Survey of Factor-Analytic Studies. New York, NY, USA: Cambridge University Press; 1993. [Google Scholar]

4. Ciarrochi J, Scott G. The link between emotional competence and well-being: a longitudinal study. British Journal of Guidance and Counselling. 2006;34(2):231243. [Google Scholar]

5. Garner PW. Emotional competence and its influences on teaching and learning. Educational Psychology Review. 2010;22(3):297-321. [Google Scholar]

6. Goleman D. Emotional Intelligence. New York, NY, USA: Bantam; 1995. [Google Scholar]

7. Goleman D. An EI-based theory of performance. In: Cherniss C, Goleman D, editors. The Emotionally Intelligent Workplace: How to Select for, Measure, and Improve Emotional Intelligence in Individuals, Groups, and Organizations. San Francisco, Calif, USA: Jossey-Bass; 2001. pp. 27-44. [Google Scholar]

8. Goleman D. Working with Emotional Intelligence. New York, NY, USA: Bantam; 1998. [Google Scholar]

9. Saarni C. The Development of Emotional Competence. New York, NY, USA: Guilford Press; 1999. [Google Scholar]

10. Saarni C. Emotional competence: a developmental perspective. In: Bar-On R, Parker JDA, editors. Handbook of Emotional Intelligence. San Francisco, Calif, USA: Jossey-Bass; 2000. pp. 68-91. [Google Scholar]

11. Salovey P, Mayer JD. Emotional intelligence. Imagination, Cognition and Personality. 1990;9: 185-211. [Google Scholar]

12. Tucker, M.L., Sojka, J.Z., Barone, F.J. \& McCarthy, A.M. (2000). Training tomorrow's leaders: Enhancing the emotional intelligence of business graduates. Journal of Education for Business, 75, 331-338.

13. Zeidner M. Intelligence and conation: current perspectives and directions for future research. In: Messick S, Collis J, editors. Intelligence and Personality: Bridging the Gap in Theory and Measurement. Mahwah, NJ, USA: Lawrence Erlbaum Associates; 2001. pp. 195-213. [Google Scholar]

14. Zeidner M, Roberts RD, Matthews G. Can emotional intelligence be schooled? A critical review. Educational Psychologist. 2002;37(4):215-231. [Google Scholar] 
Webliography

- Emotional Competence as a Positive Youth Development Construct: A Conceptual Review. Retrieved from

https://www.ncbi.nlm.nih.gov/pmc/articles/PMC3361327/\#B10

Dr. Mona Mehta,

Assistant Professor,

Department of FCRM, Faculty of Family and Community Sciences

The Maharaja Sayajirao University of Baroda, Vadodara

Email Id:mona.mehta.map@gmail

\&

Ms. Rakhi Dasgupta

Department of FCRM, Faculty of Family and Community Sciences

The Maharaja Sayajirao University of Baroda, Vadodara

Temp. Teaching Assistant

com,rakhidasgupta2@gmail.com

\&

Ms. Rutu Modi

Department of FCRM, Faculty of Family and Community Sciences

The Maharaja Sayajirao University of Baroda, Vadodara

Temp. Teaching Assistant

rutumodi4690@yahoo.com 